\title{
Esofagotomia torácica para remoção de corpo estranho associado a megaesôfago em cão
}

\author{
Daniel Serafim de Andrade Rodrigues ${ }^{*}$, Leticya Lorrayne da Silva Soares ${ }^{1}$, Renan \\ Paraguassu de Sa Rodrigues ${ }^{1}$, Maykon Martins dos Santos ${ }^{1}$, Dayse Andrade Barros ${ }^{1}$, \\ Yago Gabriel da Silva Barbosa ${ }^{2}$, Marcelo Campos Rodrigues ${ }^{3}$ \\ ${ }^{I}$ Graduando em Medicina Veterinária, Universidade Federal do Piauí, Teresina, \\ ${ }^{2}$ Médico Veterinário, Residente em clínica e cirurgia de cães e gatos, Universidade Federal do Piauí, Teresina. \\ ${ }^{3}$ Professor do Departamento de Clínica e Cirurgia Veterinária, Universidade Federal do Piauí, Teresina. \\ *Autor para correspondência, E-mail: danielserafimvet@gmail.com
}

\begin{abstract}
RESUMO. A ocorrência de complicações em cães por ingestão de corpos estranhos e obstrução do esôfago é algo relativamente comum na rotina do clínico veterinário. Ocorre com maior frequência em animais jovens devido os seus hábitos alimentares indiscriminados, porém, pode ocorrer em qualquer idade. Normalmente os corpos estranhos são encontrados alojados no esôfago torácico e a remoção ocorre na maioria dos casos através de cirurgia. Objetivou-se relatar o caso de um cão tratado cirurgicamente para remoção de um corpo estranho alojado no esôfago torácico associado a megaesôfago decorrente da obstrução do lúmen do órgão, através da esofagotomia torácica.
\end{abstract}

Palavras chave: Corpo estranho, esôfago, esofagotomia, cão

\section{Esophagotomy thoracic body removal strange to associate mega esophagus in dog}

\begin{abstract}
The occurrence of complications in dogs by ingesting foreign bodies and esophageal obstruction is relatively common in routine veterinary practice. It occurs most frequently in young animals because of their indiscriminate eating habits, however, can occur at any age. Typically the foreign bodies are found housed in the thoracic esophagus and removal occurs in most cases by surgery. The objective was to report the case of a dog treated surgically to remove a foreign body lodged in the thoracic esophagus associated with achalasia due to the body lumen obstruction, through the chest esophagotomy.
\end{abstract}

Keywords: Foreign body, esophagus, esophagotomy, dog.

\section{Introdução}

O esôfago é um órgão tubular relativamente estreito responsável por conduzir alimentos da faringe ao estômago, composto pelas porções cervical, torácica e abdominal (Dyce et al., 2004).

A ingestão de corpos estranhos (C.E.) que ficam incrustados no esôfago ocorre mais comumente nos cães jovens devido os seus hábitos alimentares indiscriminados, mas pode ocorrer em qualquer idade ou espécie animal (Bojrab, 2005). Normalmente são encontrados no trecho cranial da porção torácica, na base do

coração (aproximadamente 10\%) e no diafragma (aproximadamente 85\%) (Fossum, 2014).

Um C.E se aloja no esôfago geralmente por ser grande ou por ter uma ponta afiada que perfure a mucosa esofágica. Os C.E esofágicos mais comumente observados no cão são grandes pedaços de osso ou objetos metálicos afiados (Bojrab, 2005).

A persistência de um C.E no esôfago estimula a atividade peristáltica. Se este causar pressão excessiva no esôfago ou se permanecer no local 
por muitos dias, pode ocorrer necrose por pressão e perfuração (Fossum, 2014).

Os sinais clínicos variam e dependem da duração, da localização, do grau de obstrução e se ocorreu a perfuração do esôfago. As obstruções completas causam a regurgitação de sólidos e de líquidos, ao passo que obstruções parciais podem permitir a retenção de líquidos (Slatter, 2007, Nelson \& Couto, 2015).

Pode ainda ocorrer dispnéia aguda em casos em que o C.E está comprimindo as vias aéreas ou se desenvolveu pneumonia por aspiração, e em casos de perfuração o animal pode apresentar febre, depressão e/ou anorexia. O diagnóstico baseia-se no histórico, sinais clínicos, radiografia ou endoscopia (Nelson \& Couto, 2015).

Os C.E podem ser removidos cirurgicamente através de uma esofagotomia que é realizada quando estes não podem ser removidos por outros meios, quando o risco de perfuração esofágica ou dilaceração é elevado, ou quando há evidência de mediastinite, pleurite ou necrose (Fossum, 2014).

O esôfago torácico é de difícil acesso e requer técnicas meticulosa, pois este órgão possui particularidades anatômicas e fisiológicas que requerem manipulação cuidadosa e delicada em abordagens cirúrgicas para que não haja prejuízo de cicatrização (Barreto et al., 2006).
Objetiva-se neste artigo relatar um caso de um cão tratado cirurgicamente para remoção de um corpo estranho esofágico, alojado cranial ao diafragma e associado a megaesôfago, pela técnica cirúrgica de esofagotomia torácica.

\section{Descrição do caso}

Um cão macho da raça poodle de 5 meses de idade foi atendido no Hospital Veterinário da UFPI com sinais de disfagia e regurgitação. $\mathrm{O}$ tutor relatava que o animal apresentava dificuldade ao se alimentar, com ânsia de vômito e após ingerir alimentos os regurgitava.

Foi solicitada radiografia simples e contrastada do tórax. Na radiografia simples foi observada a presença de um corpo estranho radiopaco, com a extremidade caudal irregular e pontiaguda, localizado na porção torácica do esôfago, cranial ao diafragma, que se estende do $6^{\circ}$ ao $9^{\circ}$ espaço intercostal, com obstrução total do lúmen esofágico (Figura 1).

$\mathrm{Na}$ radiografia contrastada foi observada uma dilatação de toda a porção torácica do esôfago, com maior intensidade na região proximal a obstrução pelo corpo estranho, sendo diagnosticado como um caso de megaesôfago em decorrência da obstrução esofágica. Após o diagnóstico, o animal foi indicado à cirurgia para realização da esofagotomia torácica para remoção do corpo estranho (Figura 2).

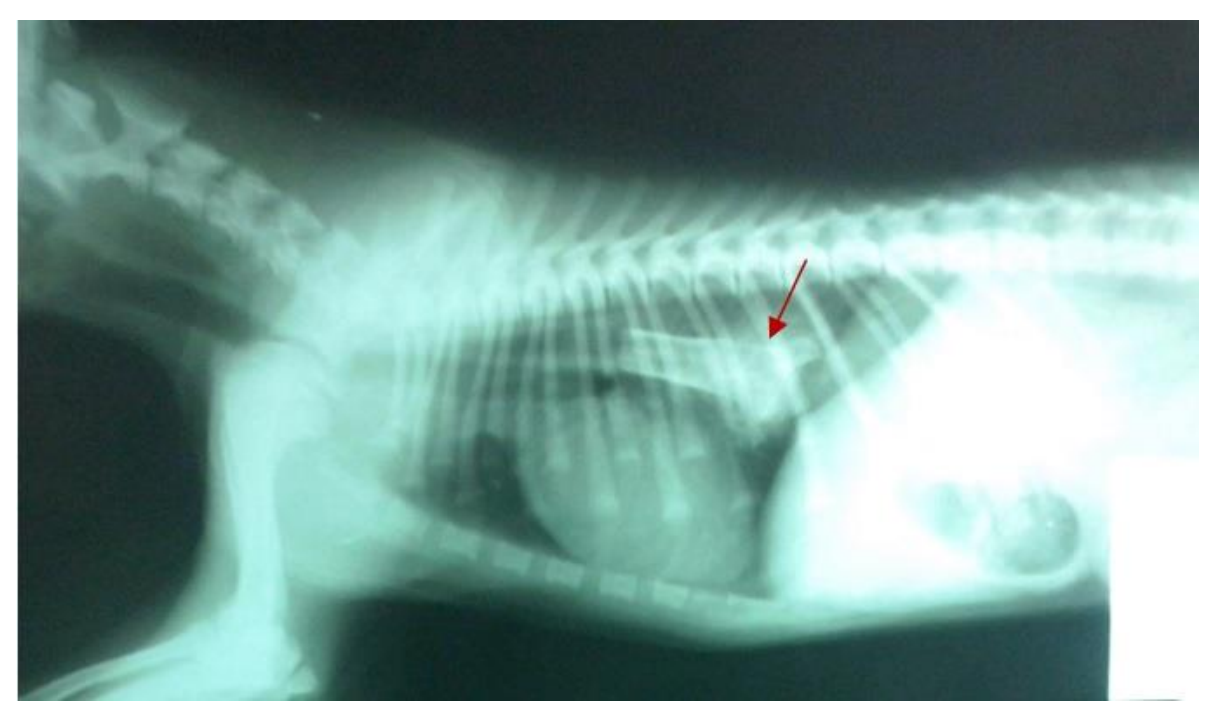

Figura 1: Radiografia simples evidenciando a presença de corpo estranho esofágico (seta) na porção torácica do esôfago, cranial ao diafragma. 


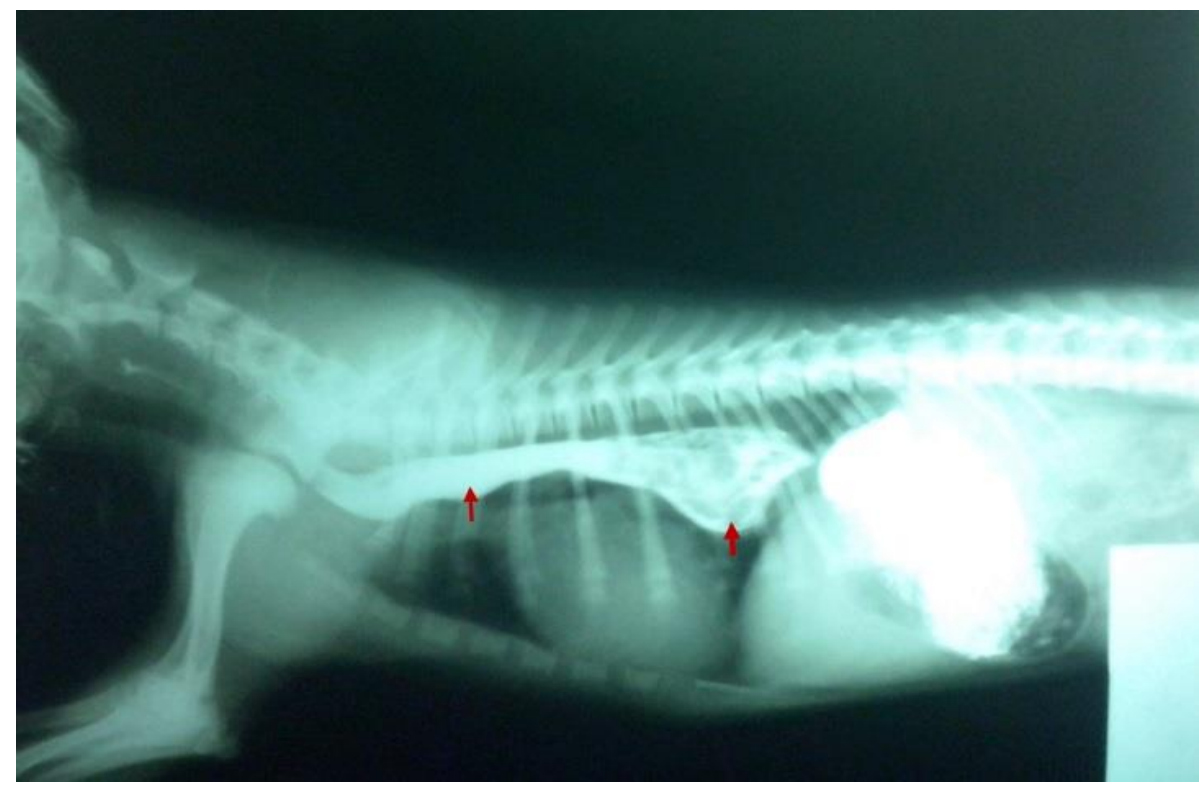

Figura 2. Radiografia contrastada evidenciando a dilatação do esôfago torácico (setas), cranial a obstrução pelo corpo estranho.

Segundo Fossum (2014) para abordar o esôfago torácico-caudal, deve-se posicionar o animal em decúbito lateral direito e fazer uma incisão no oitavo ou nono espaço intercostal, identificar e transeccionar ou rebater os músculos latíssimo dorsal, serrátil dorsal cranial, oblíquo abdominal externo e intercostal.

Foi feita tricotomia da região torácica esquerda do animal com posterior administração de medicação pré-anestésica e indução com anestesia inalatória. Foi também introduzida uma sonda oro-esofágica para facilitação da identificação do esôfago na cavidade torácica. Após anti-sepsia do sítio cirúrgico, foi realizada a toracotomia através de uma incisão vertical no oitavo espaço intercostal.

A abertura da cavidade foi facilitada com o auxílio de um afastador de Weitlaner. Conforme Barreto et al. (2006), o esôfago foi localizado com o auxílio da sonda oro-esofágica e depois de elevado cuidadosamente até a abertura do tórax, onde foi mantido com a ajuda de uma pinça hemostática com os ramos fechados passada por baixo do esôfago.

Com o fio de sutura penetrado na serosa do órgão e sustentado com auxílio de pinças hemostáticas, foi realizada a fixação do esôfago. Foi identificado o local da obstrução e realizada uma incisão longitudinal do esôfago acima do corpo estranho. Com o auxílio de uma pinça anatômica, cuidadosamente o corpo estranho foi removido do lúmen esofágico (Figura 3 ).

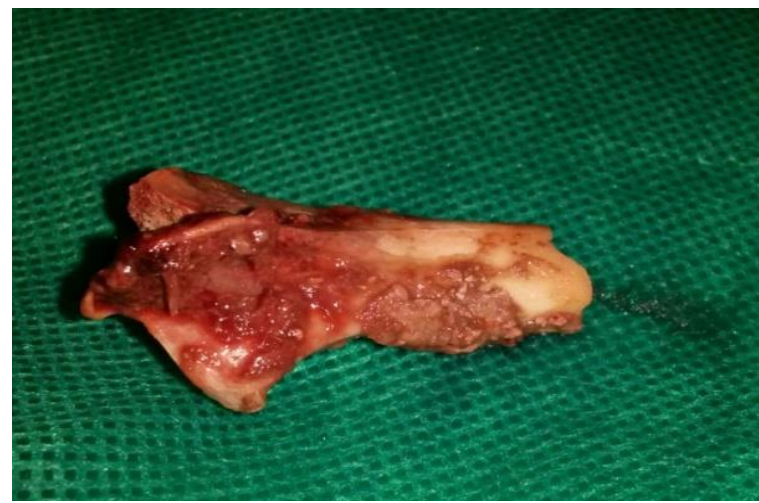

Figura 3. Corpo estranho removido do lúmen esofágico.

Após a remoção do corpo estranho foi feita a limpeza dos tecidos com solução salina e o tecido esofágico foi avaliado quanto a sua viabilidade. Constatado a viabilidade dos mesmos, foi realizada a sutura em duas camadas. Conforme Bojrab (2005), a mucosa e a submucosa foram fechadas colocando-se previamente suturas interrompidas simples com nós amarrados no interior da luz. As camadas musculares foram fechadas e uma segunda sutura utilizando pontos simples separados com nós amarrados para fora do lúmen. Após sutura do esôfago em dois planos, sutura do espaço intercostal e tecidos adjacentes foram feita o restabelecimento da pressão negativa intratorácica através da remoção de ar utilizando uma seringa de $20 \mathrm{ml}$ e um cateter acoplado a uma torneira de três vias.

No pós-cirúrgico, o animal foi medicado com cimetidina e metaclopramida para impedir o 
refluxo de ácido gástrico no interior do esôfago. Além disso, suspendeu-se o fornecimento de alimento e água ao paciente por 48 horas, sendo mantido por soluções nutritivas e hidroeletrolíticas por via endovenosa. Após as 72 horas, o animal passou a ser alimentado por dieta com alimentos pastosos.

\section{Discussão}

Como o descrito por Bojrab (2005), o corpo estranho incrustado no esôfago, do presente relato, era composto de um grande pedaço de osso e ocorreu em um animal jovem. A disfagia e regurgitação de sólidos e líquidos foram os principais sinais clínicos manifestados pelo animal conforme o descrito por Slatter (2007) e Nelson \& Couto (2015). A sutura do esôfago foi realizada em duas camadas, com fechamento da mucosa e submucosa com sutura interrompidas simples e a camada muscular em pontos simples separados. Contudo, segundo Quessada et al. (1995) também se pode realizar sutura extramucosa em pontos separados simples e plano único no esôfago torácico de cães com resultados satisfatórios tanto em incisões transversais como longitudinais.

Segundo Barcellos et al. (2000) cães alimentados por nutrição enteral por sonda gástrica implantada por gastrostomia endoscópica percutânea, durante os primeiros sete dias após esofagotomia, apresentam melhor cicatrização da ferida cirúrgica em comparação com alimentação por sonda faringogástrica e alimentação por dieta tradicional. $\mathrm{O}$ melhor resultado se deve provavelmente à ausência de movimentos de deglutição do bolo alimentar sobre a ferida cirúrgica. Ainda, segundo Barcellos et al. (2000) na ausência de um endoscópio, a dieta tradicional resulta em cicatrização de melhor qualidade do que o uso alimentação por meio de tubo de faringostomia. Dessa forma optou-se pela utilização da dieta tradicional tendo em vista a obtenção de resultados satisfatórios por essa técnica e a indisponibilidade do uso de endoscópio.

\section{Conclusão}

A esofagotomia torácica requerer cuidados especiais que vão do pré-operatório ao póscirúrgico, cuja abordagem cirúrgica deve ser cuidadosa e delicada a fim de evitar complicação como a estenose esofágica durante a cicatrização da ferida.

\section{Referências Bibliográficas}

Barcellos, H. H. A., Silva Filho, A. d. P. F. \& Beck, C. A. C. (2000). Influência de três tipos de vias de fornecimento de dietas pósoperatórias na cicatrização de esofagotomia cervical em cães. Brazilian Journal of Veterinary Research and Animal Science, 37, 382-387.

Barreto, F. M., Quessada, A. M., Cardoso, F. T. S., Soares, F. d. C. L. L., Sousa, A. A. R., Oliveira, E. H. S., Muniz, L. M. R., Pirolo, J., Sequeira, J. L. \& Santos Teixeira, E. M. (2006). Técnica de exposição e fixação do esôfago torácico em cães. Acta Scientiae Veterinariae, 34, 153-157.

Bojrab, M. J. (2005). Técnicas atuais em cirurgia de pequenos animais. Editora Roca, São Paulo.

Dyce, K. M., Wensing, C. J. G. \& Sack, W. O. (2004). Tratado de anatomia veterinária. Elsevier Brasil, São Paulo.

Fossum, T. W. (2014). Cirurgia de pequenos animais, 4th edn. Elsevier Brasil, São Paulo.

Nelson, R. W. \& Couto, C. G. (2015). Medicina interna de pequenos animais. Elsivier Editora, Amsterdan.

Quessada, A. M., Muniz, L. M. R., de Sousa, J. M. \& Drumond, K. O. (1995). Sutura extramucosa em pontos separados simples e plano único no esôfago torácico de cães. Veterinária em Foco, 7, 165-174.

Slatter, D. H. (2007). Manual de cirurgia de pequenos animais. Manole, São Paulo.

\author{
Article History: \\ Received 31 March, 2016 \\ Accepted 1 May, 2016 \\ Available online 22 June, 2016
}

License information: This is an open-access article distributed under the terms of the Creative Commons Attribution License, which permits unrestricted use, distribution, and reproduction in any medium, provided the original work is properly cited 